\title{
Severe Gastrointestinal Bleeding and Thrombocytopenia in a Child With an Anti-GATA1 Autoantibody
}

\author{
LIESBETH DE WAELE, KATHLEEN FRESON, SOPHIE LOUWETTE, CHANTAL THYS, CHRISTINE WITTEVRONGEL, \\ RITA DE VOS, ANNE DEBEER, AND CHRIS vAN GEET
}

\author{
Departments of Pediatrics [L.W., K.F., S.L., C.Y., C.W., C.F.], Pathology [R.V.] and Neonatology [A.D.], Catholic University of Leuven, \\ Leuven, 3000, Belgium
}

\begin{abstract}
We describe a patient, who developed during the first week of life petechiae and hematomas caused by severe thrombocytopenia and gastrointestinal bleeding due to multiple small gastric hemangiomata. Bone marrow examination showed hypermegakaryocytosis and dysmegakaryopoiesis. Alloimmune thrombocytopenia was excluded. Only 3 y later, platelet counts normalized and bleedings disappeared but small skin hemangiomata remained. Electron microscopy showed enlarged round platelets with a paucity of alpha granules similar as in GATA1-deficient patients but no GATA1 mutation was found. Immunoblot analysis showed a strong interaction between patient Igs and recombinant GATA1, GATA2, and the $\mathrm{N}$ finger (Nf) of GATA1. The lymphocyte transformation test with recombinant GATA1Nf was positive. In vitro culturing of normal $\mathrm{CD} 4^{+}$cells with purified patient Igs showed a decreased number of megakaryocyte colonies but an increased overall size of the colonies compared with control Igs. Mice injected with patient Igs showed a reduced platelet count compared with mice injected with control Igs. Thrombopoiesis was also reduced after injection of patient Igs in transgenic zebrafish compared with control Igs. In conclusion, this study is the first report of an anti-GATA1 autoantibody leading to severe thrombocytopenia and gastrointestinal bleeding from multiple pinpoint hemangiomata. (Pediatr Res 67: 314-319, 2010)
\end{abstract}

$\mathrm{T}$ The GATA nuclear transcription factors comprise a family of proteins which bind the DNA sequence (A/ T)GATA(A/G) via a highly conserved zinc finger domain (1). Currently, six GATA family members have been identified in mammals, which are grouped according to their expression profile as being hematopoietic (GATA1-3) or nonhematopoietic (GATA4-6). Briefly, GATA1 is necessary for the erythroid, megakaryocytic, and mast cell lineages (2-4), GATA2 for the proliferation of uncommitted hematopoietic precursors and endothelial cells $(4,5)$, and GATA3 for the T-lymphoid lineage $(6,7)$. The nonhematopoietic transcription factors are expressed in the heart, intestine, and diverse tissues such as ovary, lung, liver, and spleen $(8,9)$.

The X-linked transcription factor GATA1 contains three functional domains: a $\mathrm{N}$-terminal transactivation domain and

Received June 24, 2009; accepted November 2, 2009.

Correspondence: Kathleen Freson, Ph.D., Center for Molecular and Vascular Biology, University of Leuven, Herestraat 49, B-3000 Leuven, Belgium; e-mail: kathleen.freson@ med.kuleuven.be

Supported by the "Excellentie financiering KULeuven" (EF/05/013), by research grants G.0453.05, G.0743.09 and G.0124.02 from the FWO-Vlaanderen (Belgium) and by GOA/2009/13 from the Research Council of the University of Leuven (Onderzoeksraad K.U.Leuven, Belgium). C.v.G. is holder of the Bayer and Norbert Heimburger (CSL Behring) Chairs. two zinc fingers known as the $\mathrm{C}$ finger and $\mathrm{N}$ finger (Nf). The $\mathrm{C}$ finger is sufficient for binding DNA, whereas the $\mathrm{Nf}$ contributes to DNA binding and is essential in recruitment of the essential transcriptional cofactor friend of GATA1 (FOG1) $(10-13)$. GATA1 deficiency due to a germline missense mutation in the Nf of GATA1 causes a variable degree of $\mathrm{X}$-linked dyserythropoiesis with moderate to severe macrothrombocytopenia (14-23). All described mutations affect FOG1 interaction, except for the R216Q mutation that interferes with DNA binding rather than with FOG1 interaction. In severe phenotypes, lethal bleedings occur mainly early in life. GATA1-deficient patients have giant dysfunctional platelets with fewer alpha granules and membrane inclusions $(15,16)$. Bone marrow examination reveals a hyperproliferation of hypercellular, small, dysplastic megakaryocytes but no mature megakaryocytes $(15,16)$.

Here, we describe a girl with refractory life-threatening macrothrombocytopenia, dyserythropoiesis, and gastrointestinal hemangiomata resulting in severe and multiple gastrointestinal bleedings during the first months of her life. In the patient's serum, an anti-GATA1 autoantibody was detected. The characteristics of this anti-GATA1 autoantibody were analyzed in relation to its identity and functional consequences toward megakaryopoiesis.

\section{METHODS}

Hematological counts and platelet studies. Peripheral EDTA anticoagulated blood samples were obtained from the patient and the retro-orbital sinus of anesthetized nonobese diabetic severe combined immunodeficiency (NOD/ SCID) mice. An aliquot of blood was analyzed on an automated cell counter (Cell-Dyn 1300; Abbott Laboratories, Abbott Park, IL) to determine leukocyte, erythrocyte, and platelet counts; hematocrit; and $\mathrm{Hb}$ levels. Blood samples from the patient were obtained after informed consent. Thrombopoietin (TPO) levels were determined in human EDTA plasma samples using a commercially available kit (R\&D Systems Inc., Minneapolis, MN). Morphologic and functional platelet studies were performed as described $(15,24)$. Platelet aggregation was performed on two dual-channel Chrono-Log Aggregometers (Chronolog Corp., Havertown, PA) as described $(17,24)$.

Genetic screening. The GATA1 gene was screened as described $(15,16)$. All MPL exons and exon/intron boundaries were screened for mutations at genomic DNA from the patient. Primer sequences and PCR conditions are available on request.

Abbreviations: FOG1, friend of GATA1; GST, glutathione S-transferase; HEK, human embryonic kidney; LTT, lymphocyte transformation test; Nf, $\mathrm{N}$-finger; NOD/SCID, nonobese diabetic severe combined immunodeficiency; TPO, thrombopoietin 
Immunoblot analysis. GATA1Nf(residues 197-251)-glutathione Stransferase (GST) fusion protein, GST, complete GATA1(residues 1-413)GST, and complete GATA2(residues 1-466)-GST were expressed in Escherichia coli and purified by affinity chromatography on immobilized glutathione as described $(15,16)$. The proteins were resolved by SDS/PAGE and transferred to Hybond ECL (enhanced chemiluminescent)-nitrocellulose membrane (Amersham Biosciences, Freiburg, Germany). Blots were revealed with the purified patient or control Igs $(50 \mu \mathrm{g})$ and a secondary rabbit horse radish peroxidase-coupled antihuman $\operatorname{IgG}$ and stained with Western blotting ECL detection reagent (GE Healthcare Life Sciences, Uppsala, Sweden). Patient and control (pooled from three unrelated normal individuals; control Igs) Igs were purified by protein A-chromatography, taking care to collect acid-eluted antibodies in $1 \mathrm{mM}$ Tris- $\mathrm{HCl}$ buffer, $\mathrm{pH}$ 8. From the patient plasma was pooled from three samples at 5, 8, and 12 mo (patient Igs) and after remission plasma was pooled from two samples after 50 mo (postpatient Igs). Blots were revealed with a mouse monoclonal GATA2 antibody (CG296; Santa Cruz Biotechnology, Santa Cruz, CA) or a rabbit polyclonal anti-GATA1Nf antibody produced in our laboratory on injection of rabbits with GATA1Nf coupled to GST. The antibody GATA1Nf was purified on protein A Sepharose beads (Amersham Biosciences) and controlled for its specificity by detection of GATA1Nf-GST. The Nf is highly homologous between different GATA factors and therefore our GATA1Nf antibody defects both GATA1 and GATA2 after transfection of HEK293 cells with pcDNA3.1 (Invitrogen) vectors containing the full length GATA1 or GATA2.

Generation and quantification of megakaryocyte colonies. Human $\mathrm{CD} 4^{+}$cells were isolated from cord blood by magnetic cell sorting (Miltenyi Biotec, Bergisch Gladbach, Germany). Human CD34 ${ }^{+}$cells $\left(1 \times 10^{4}\right)$ were cultured in Megacult-C 04973 and Methocult 04964, according to the manufacturer's instructions (Stem Cell Technologies, Vancouver, BC, Canada) with the addition of patient or control Igs $(1 \mu \mathrm{g} / \mu \mathrm{L})$. The number of megakaryocyte colonies [colony-forming units-megakaryocytes (CFU-MK)] was determined in a semisolid culture system using a commercially available kit (StemCell). The total number of megakaryocyte colonies was counted $12 \mathrm{~d}$ later using a light microscope (Leica DM RBE, Wetzlar, Germany) in cultures performed in triplicate. Megakaryocytes were identified as large cells with lobulated nuclei and basophilic staining. The Methocult culture system was used for colony-forming cell (CFC) assays to detect erythroid (burst-forming units-erythrocytes) and granulocyte/monocyte progenitors (colony-forming units-granulocytes and monocytes) at d 14. Slides were photographed at $20 \times / 0.5$ magnification with a Zeiss Axiocam MRc camera and captured with Zeiss Axiovision (Carl Zeiss, Jena, Germany).

Lymphocyte transformation test. This was carried out using the standard microculture technique (25) with antigen dilution series of recombinant GST or GATA1Nf-GST. Results were expressed as stimulation index, i.e. the counts per minute obtained with antigen stimulation, divided by the counts per minute, and obtained without addition of antigen.

Injection of Igs in NOD/SCID mice. We administered $1 \mathrm{mg} / \mathrm{kg}$ purified Igs from the patient or normal controls s.c. at $\mathrm{d}-3$ and 0 to male NOD/SCID mice ( $n=3$ in each group; 6 wk of age). At different time intervals, blood was drawn for cell counts as described earlier. Animal procedures and experiments were approved by the Animal Ethical Committee of the University of Leuven.

Injection of Igs in transgenic zebrafish. General maintenance and staging of the zebrafish were carried out according to general instructions (26). Embryos were maintained in egg water $(350 \mu \mathrm{S}$ marine salts Seachem, 2 $\mathrm{mg} / \mathrm{L}$ methylene blue) until the appropriate stage. The approximate stages are given in days postfertilization (dpf) at $28^{\circ} \mathrm{C}$ according to morphologic criteria (27). A well-characterized transgenic zebrafish line with fluorescently labeled thrombocytes (28), where green fluorescent protein (GFP) expression is under the control of the CD41 promoter, were used to inject $1 \mathrm{ng}$ of purified control or patient Igs in each embryo. Embryos (at 2 and 3 dpf) were analyzed with a fluorescent microscope (Zeiss LSM 510 Confocal Microscope, Heidelberg, Germany). After removing the chorion and yolk from the embryos, 15 embryos were dissolved for each condition in a lysis buffer containing $1 \%$ igepal CA-630 (Sigma Chemical Co., St. Louis, MO), 1 mM EDTA, and one protease inhibitor cocktail tablet/50 mL (Roche Applied Science, Indianapolis, IN) with $10 \mathrm{~min}$ sonication. Protein fractions $(50 \mu \mathrm{g})$ were resolved by SDS/PAGE and blots were revealed with a goat polyclonal anti-GFP antibody (Rockland immunochemicals Inc., Gilbertsville, PA) and the anti-GATA1Nf antibody.

Statistics. We used GraphPad InStat 3.01 software (GraphPad Software Inc., San Diego, CA). Continuous variables with little to mild skewness were summarized as mean $\pm \mathrm{SD}$ and compared by means of the Student $t$ test for unpaired data. To determine differences in platelet counts after injection of Igs in NOD/SCID mice, a one-way ANOVA test was used, complemented with Bonferroni's multiple comparison $t$ test to identify statistical differences at each individual time point. Data were considered significant in all cases when the $p$ value was $<0.05$.

\section{RESULTS}

Patient description. The patient was born as second child of healthy, nonrelated parents. She presented at birth with a hematoma and thrombocytopenia $\left(74 \times 10^{9}\right.$ platelets/L). Her mother was carrier of hepatitis B and therefore a hepatitis B vaccination and anti-hepatitis B Igs were administered immediately after birth. In the following $2 \mathrm{wk}$, the platelet count decreased further to $21 \times 10^{9}$ platelets/L (Table 1 and Fig. $1 A)$. Alloimmune thrombocytopenia was excluded because maternal anti-human platelet antigen antibodies were not present, and there was no mismatch between maternal and neonatal human platelet antigens. Other characteristics of autoimmune disorders were absent (ANA, ANCA, etc). She was treated with i.v. administration of Igs without any therapeutic effect and the platelet count only transiently increased during 1 or $2 \mathrm{~d}$ after platelet transfusion. On d 15, she presented with massive hematemesis and melena. Gastroscopy revealed severe hemorrhagic gastritis with ulcerations and small inflammatory polyps. A peripheral blood smear showed deep macrothrombocytopenia, features of dyserythropoiesis, an increased number of myeloid precursors, and no basophils. Bone marrow examination (at $6 \mathrm{wk}$ and $2.5 \mathrm{mo}$ ) showed dysmegakaryopoiesis and hypermegakaryocytosis, similar as we have seen in GATA1-deficient patients $(15,16)$. Because of multiple life-threatening bleeding episodes with hypovolemic shock and need for polytransfusion of platelets and packed cells intensification of therapy with recombinant activated FVII (Novoseven, Novo Nordisk, Bagvaerd, Denmark) was administered temporarily. A second gastroscopy showed multiple actively bleeding pinpoint angiomata $(<2 \mathrm{~mm})$ in an

Table 1. Hematological profile

\begin{tabular}{|c|c|c|c|c|c|c|c|c|c|c|c|c|}
\hline & $\begin{array}{c}\mathrm{RBC} \\
\left(\times 10^{12} / \mathrm{L}\right)\end{array}$ & $\begin{array}{c}\mathrm{Hb} \\
(\mathrm{g} / \mathrm{dL})\end{array}$ & $\begin{array}{l}\text { Hct } \\
(\%)\end{array}$ & $\begin{array}{l}\mathrm{MCV} \\
\text { (fL) }\end{array}$ & $\begin{array}{c}\mathrm{MCH} \\
(\mathrm{pg})\end{array}$ & $\begin{array}{c}\text { Ret } \\
\left(\times 10^{9} / \mathrm{L}\right)\end{array}$ & $\begin{array}{l}\text { RDW } \\
(\%)\end{array}$ & $\begin{array}{c}\text { WBC } \\
\left(\times 10^{9} / \mathrm{L}\right)\end{array}$ & $\begin{array}{c}\text { Neut } \\
\left(\times 10^{9} / \mathrm{L}\right)\end{array}$ & $\begin{array}{c}\text { Lym } \\
\left(\times 10^{9} / \mathrm{L}\right)\end{array}$ & $\begin{array}{c}\text { Plt } \\
\left(\times 10^{9} / \mathrm{L}\right)\end{array}$ & $\begin{array}{c}\text { MPV } \\
\text { (fL) }\end{array}$ \\
\hline Normal value & $3.7-5.3$ & $11-13.5$ & $33-39$ & $75-86$ & $23-31$ & $20-100$ & $11.7-14.5$ & $6.0-17.5$ & $2.5-7.8$ & $4.0-13.5$ & $150-450$ & $9-13$ \\
\hline $2 \mathrm{mo}$ & 2.75 & 8.3 & 24 & 87.3 & 30.2 & 81 & 15.7 & 9.18 & 2.1 & 6.2 & 49 & $>13$ \\
\hline $12 \mathrm{mo}$ & 3.21 & 8.8 & 28.5 & 88.8 & 27.4 & 122 & 17.0 & 6.4 & 3.7 & 2.4 & 29 & $>13$ \\
\hline $24 \mathrm{mo}$ & 4.58 & 12.6 & 37.9 & 82.8 & 27.5 & 48 & 14.0 & 8.4 & 2.4 & 5.7 & 50 & $>13$ \\
\hline $36 \mathrm{mo}$ & 4.75 & 13.0 & 37.4 & 78.7 & 27.4 & 48 & 13.6 & 8.6 & 2.9 & 5.1 & 55 & 10.9 \\
\hline $54 \mathrm{mo}$ & 4.72 & 13.1 & 39.3 & 83.3 & 27.8 & 39 & 13.0 & 9.3 & 4.0 & 4.8 & 213 & 9.5 \\
\hline
\end{tabular}

RBC, red blood cell number; Hct, hematocrit; MCV, mean corpuscular volume; $\mathrm{MCH}$, mean corpuscular hemoglobin; Ret, reticulocyte cell number; RDW, red blood cell distribution width; WBC, white blood cell number; Neut, neutrophil cell number; Lym, lymphocyte cell number; Plt, platelet number; MPV, mean platelet volume (values above $13 \mathrm{fL}$ are not measured). 

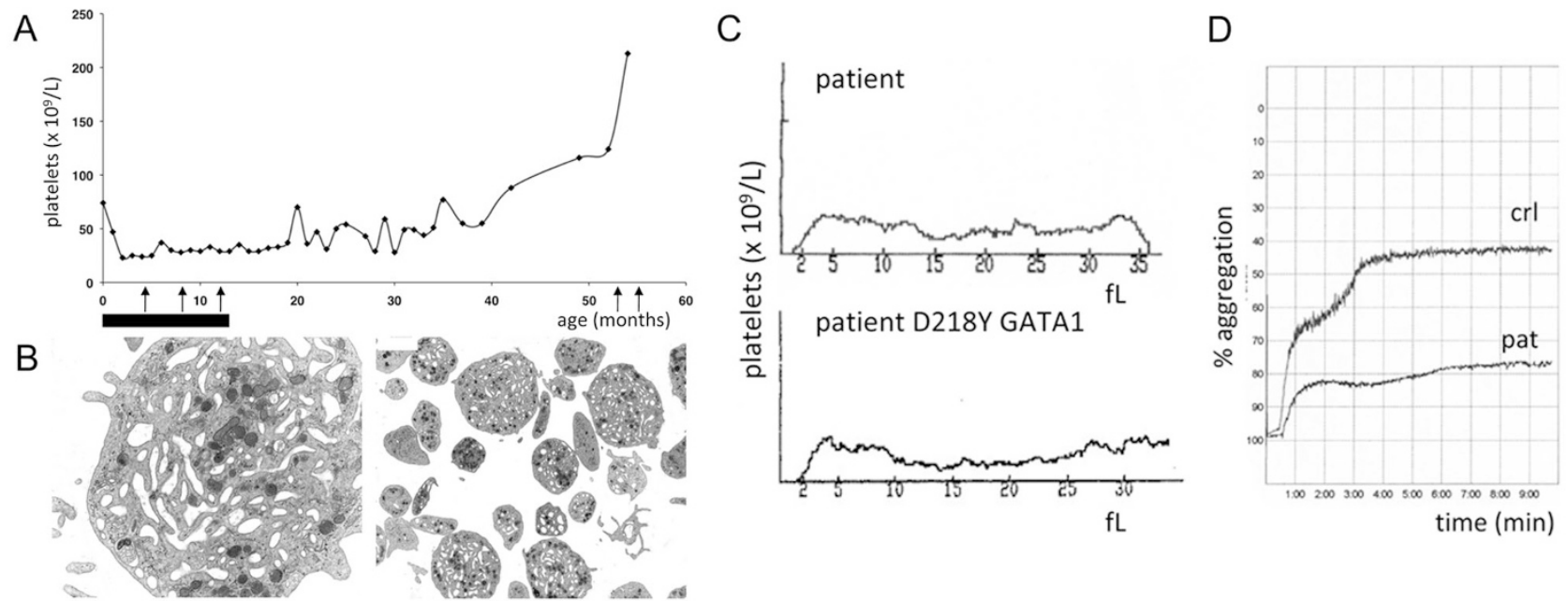

Figure 1. Platelet counts, morphology, and function. A, The follow-up of the patient's platelet count in function of her age. The black bar indicates the time period in which the patient received regular platelet transfusions. The arrows indicate the patient's age at which plasma samples were collected for Ig purification. $B$, Electron microscopy showing giant round platelets with a paucity of alpha granules. The magnifications are 25,000 (right) and 7,800 (left). C, Platelet hematological count profile of the patient compared with another patient with a GATA1 D218Y N finger mutation. $D$, Ristocetin-induced platelet agglutination in platelet-rich plasma from a control subject $(\mathrm{crl})$ and the patient $(\mathrm{pat})$ using $50 \times 10^{9}$ platelets/L.

otherwise normal gastric mucosa. Duodenoscopy and coloscopy were normal. Abdominal angiography and an abdominal computed tomography scan could not reveal any abnormal vasculature. Steroids were started and hemangiomata were repeatedly laser photocoagulated ( $>40$ times). Nevertheless, the severe thrombocytopenia and recurrent gastrointestinal bleedings were still equally present and empirical therapy with s.c. interferon alfa2a (Roferon, Roche, Basel, Switzerland) was started 3 mo after birth. Platelet counts remained low $\left(29 \times 10^{9}\right.$ platelets/L), but the gastrointestinal bleeding improved. Because of the very fragile condition of the gastrointestinal mucosa every viral gastrointestinal infection resulted in macroscopic blood loss. Interferon therapy was gradually decreased and stopped at the age of $1.5 \mathrm{y}$. After $2 \mathrm{y}$, the patient, who was still thrombocytopenic, developed small superficial skin hemangiomata on the lower back, abdomen, and upper legs, histopathologically described as benign endothelial proliferations. Remarkably, during the last $2 \mathrm{y}$, her platelet count recovered slowly with currently normalization $\left(213 \times 10^{9}\right.$ platelets/L) at the age of $4.5 \mathrm{y}$ (Table 1), coinciding with disappearance of the anti-GATA1 autoantibody. Regression of hemangiomata in the gastric mucosa and skin was established. Her parents have a normal platelet count and mean platelet volume (MPV). There was never any sign of Kasabach-Merritt syndrome with normal fibrinogen and D-dimer levels. There was also no family history of an autoimmune disease.

Morphologic and functional platelet studies. Electron microscopy revealed enlarged platelets with membrane inclusions and a paucity of alpha granules (Fig. $1 B$ ). These platelets are highly similar to platelets we described earlier in patients with GATA1 Nf missense mutations $(15,16)$. Figure $1 C$ shows the platelet count profile of the patient and our previously described patient with a D218Y Nf GATA1 mutation (16). Further similarities with GATA1 deficiency could also be shown in the functional platelet tests as the patient has a reduced ristocetin-induced agglutination but a normal response to ADP (16) (Fig. 1D). The parents had normal platelet aggregations. The functional platelet response in the patient normalized as her platelet count and MPV normalized.

Genetic screening and autoantibody detection. Because of the strong similarities with GATA1-deficient boys and the knowledge that GATA1 defects could result in skewed $\times$ chromosome inactivation (16), we screened the GATAl gene in the patient but found no abnormalities. To exclude congenital amegakaryocytic thrombocytopenia, mutations in the $M P L$ gene were excluded. TPO levels in peripheral blood were determined on multiple occasions with slightly elevated levels of 325 and $310 \mathrm{pg} / \mathrm{mL}$ at 5 and $8 \mathrm{mo}$, respectively, and 105 $\mathrm{pg} / \mathrm{mL}$ at 12 mo (normal range between non detectable and $228 \mathrm{pg} / \mathrm{mL}$ ).

Igs were purified from pooled plasma samples from the patient during the first months and after remission (Fig. 1A) and from three unrelated normal controls. We screened these Igs for the presence of an autoantibody against recombinant GATA1. A GST fusion protein with the GATA1Nf or GST alone was produced and purified via glutathione-sepharose beads. The patient Igs recognized the recombinant GATA1Nf but not GST alone as determined via immunoblot analysis (Fig. 2A). Control Igs do not detect the GATA1Nf. Because the GATA zinc fingers are highly similar between the different hematopoietic GATA transcription factors; the autoantibody could cross-react with other GATA factors. Indeed, GST fusion proteins coupled with full length GATA1 and GATA2 interact with the patient Igs but not with the control Igs (Fig. $2 B$ ). The patient Igs in remission did not show any GATA binding affinity (data not shown).

Lymphocyte transformation test. To determine the presence of a population of lymphocytes in the patient who reacts with the GATA1Nf, a lymphocyte transformation test (LTT) was performed when the patient was 26-mo old. The LTT was done with the fusion protein GATA1Nf-GST and with GST as 


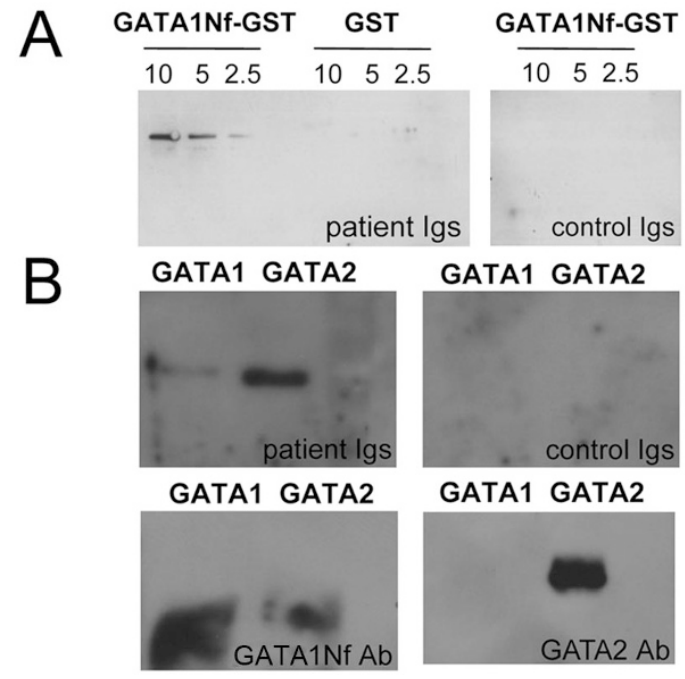

Figure 2. In vitro characterization of the anti-GATA1 autoantibody. A, Recombinant GATA1Nf-GST protein and GST were separated by SDS/ PAGE. The incubation with patient Igs resulted in a positive detection of the GATA1Nf (right) but not with the control Igs (left). B, Recombinant GATA1GST, GATA2-GST, and GST were separated by SDS/PAGE. An interaction between patient Igs and GATA1 and GATA2 could be detected, but there was no interaction with the control Igs (upper). Blots with control antibodies were also performed (lower).

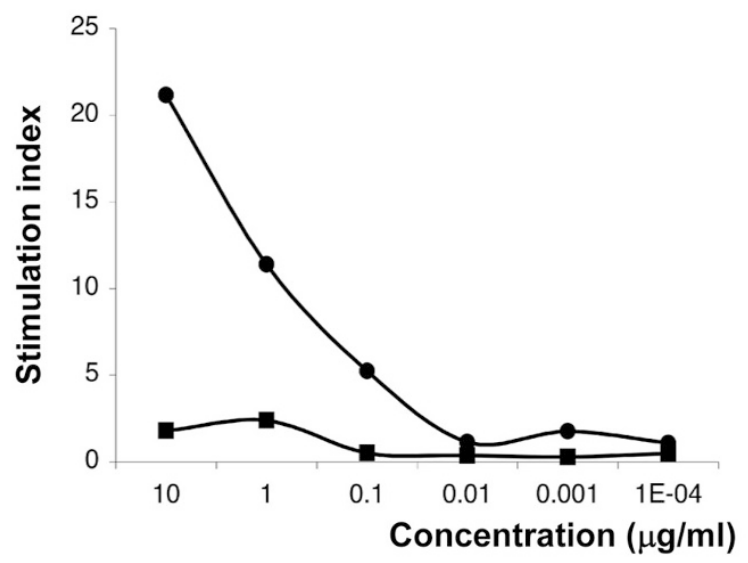

Figure 3. LTT for the patient using stimulation with recombinant GST ( and GATA1Nf-GST $(\bullet)$ at the indicated concentrations.

negative control. The results indeed only indicate the presence of a population of lymphocytes producing antibodies against GATA1Nf but not against GST (Fig. 3). The LTT was repeated when the patient was 5-y old but then the proliferative response to GATA1Nf-GST was not different from the response to GST.

Functional characterization of the anti-GATA1 autoantibody. In vitro cultures of normal cord blood-derived CD $34^{+}$ hematopoietic stem cells incubated with the patient Igs not only resulted in a reduced number of CFU-MK colonies (Fig. 4A) but also induced hyperproliferation of megakaryocyte colonies as larger and more dense colonies are formed in the presence of patient Igs (Fig. $4 A$ and $B$ ). There were no significant differences in the size and number of granulocyte or erythroid colonies. To strengthen our findings concerning the influence of the anti-GATA1 auto-
A
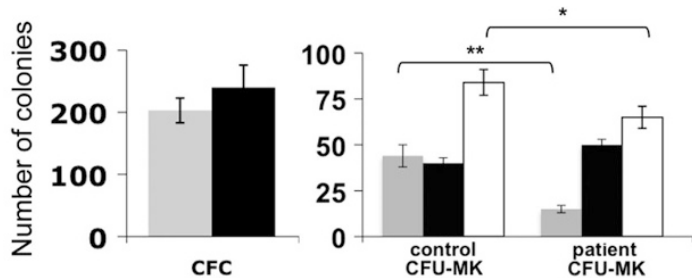

$\mathrm{B}$

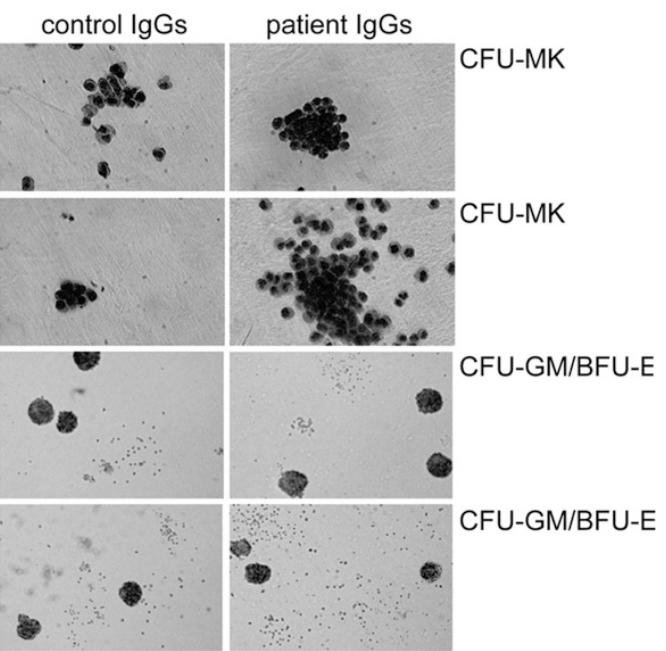

Figure 4. Ex vivo characterization of the anti-GATA1 autoantibody. A, Total amount of CFC on d 14 from CD34 ${ }^{+}$cells incubated with control (gray) or patient (black) Igs (right). Day 12 differentiated megakaryocyte colonies (CFU$\mathrm{MK}$ ) in the presence of patient or control Igs (left) counted for less (gray) or $>10$ cells per colony (black) or the total amount (white). Bars represent the mean \pm $\mathrm{SD}\left({ }^{*} p<0.05 ; * * p<0.001\right) . B$, Pictures of the CFU-MK and CFU-GM/BFU-E colonies after incubation with control or patient Igs. Magnification $20 \times$.

antibody on megakaryopoiesis and to prove that the antibody can enter the bone marrow environment, NOD/SCID mice were injected twice s.c. with patient or control Igs. Interestingly, patient but not control Igs significantly reduced the platelet counts in mice at d 10 and 13 after the first injection (Fig. 5A). No differences were seen in the other blood cell lineages or the Hb level. The MPV did not differ between the two groups, and there were no differences in tail bleeding times. Moreover, the mice remained healthy during the course of the experiment and there was no evidence for gastrointestinal bleeding.

Because we only had a limited amount of the patient's antibody left, we could neither increase the antibody dosage nor repeat this experiment. Therefore, we injected the patient and control Igs in $\mathrm{CD} 41^{+}$transgenic zebrafish (28). The zebrafish embryo's were analyzed at $2 \mathrm{dpf}$ using fluorescent microscopy showing a reduced number of thrombocytes formed in embryos injected with the patient Igs (Fig. 5B). These differences in zebrafish thrombocytes were quantified at $3 \mathrm{dpf}$ by immunoblot analysis of embryo extracts using an anti-GFP antibody. The GFP signal was reduced in the embryos injected with the patient Igs compared with control Igs (Fig. 5C). These differences were not seen using patient Igs purified when the patient was in remission. There were no differences in GATA expression between the two groups of embryos using our polyclonal antiGATA1Nf antibody (Fig. 5C). 


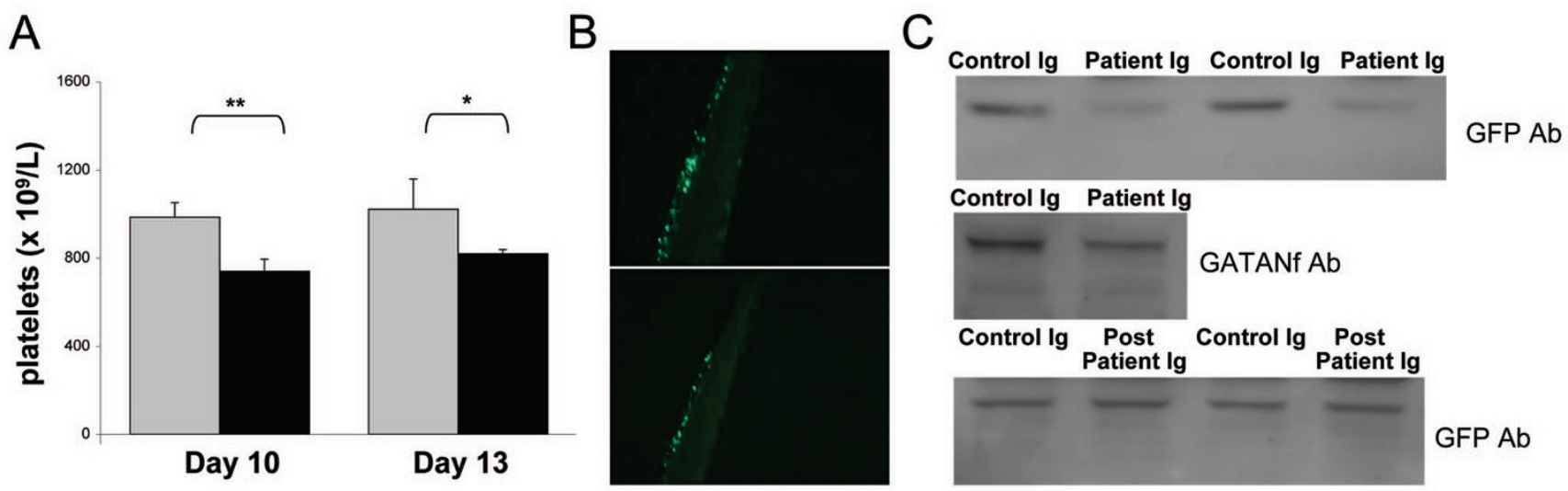

Figure 5. In vivo characterization of the anti-GATA1 autoantibody. $A$, Platelet count in mice ( $n=3$ in each group) after administration of control (gray) or patient (black) Igs on $\mathrm{d}-3$ and 0 . Each point represents the mean platelet count from $\pm \mathrm{SD} * p<0.05$; ** $p<0.01$; by ANOVA. $B$, Fluorescent images showing GFP-positive thrombocytes in zebrafish embryos $2 \mathrm{dpf}$ after injection with control (right) or patient (left) Igs (experiment in duplicate). $C$, Immunoblot analysis of embryo lysates $3 \mathrm{dpf}$ after injection with patient (before and after remission; post) or control Igs using the indicated antibodies.

\section{DISCUSSION}

We here describe a patient, who developed already during her first week of life petechiae and hematomas caused by severe macrothrombocytopenia and massive gastrointestinal bleeding from multiple pinpoint gastric hemangiomata. Alloimmune thrombocytopenia and congenital amegakaryocytic thrombocytopenia were excluded. Toxoplasma gondii, other viruses (HIV, measles, and more), rubella, cytomegalovirus, and herpes simplex (TORCH) screening and additional investigations for autoimmune disorders were negative. ZollingerEllison was excluded in the presence of normal gastrin levels. Electron microscopy of platelets revealed enlarged round platelets with a paucity of alpha granules, similar to what has been observed in patients with GATA1 deficiency, but the patient carried no GATAl mutations. The mother had a normal platelet count and size, normal TPO levels, and normal functional platelet tests. In vitro experiments with patient purified Igs demonstrated the presence of an anti-GATA1 autoantibody. Immunoblot analysis showed a strong interaction between patient Igs and recombinant GATA1, GATA2, and the Nf of GATA1.

A LTT usually measures the proliferation of lymphocytes to a protein (e.g. drug) in vitro demonstrating a previous in vivo sensitization. In our patient, the LTT with recombinant GATA1Nf was positive at the moment of detection of the antibody in the patient's serum, but when the antibody disappeared, no differences could be observed in the proliferation response toward GATA1Nf and a control. However, it is known that a LTT is not the most sensitive detection method for a population of memory cells.

We hypothesize that anti-GATA1 autoantibodies in the bone marrow of our patient resulted in hyperproliferation of megakaryocytes without normal differentiation and platelet formation. In vitro culturing of normal CD $34^{+}$cells with purified patient Igs showed a decreased number of total megakaryocyte colonies but an increased overall size of the colonies compared with control Igs. NOD/SCID mice injected with patient Igs showed a reduced platelet count at d 10 and 13 after injection of the antibody but no signs of gastrointestinal bleedings. Thrombopoiesis was also reduced after injection of patient Igs in transgenic zebrafish with GFP-labeled thrombocytes compared with control Igs. The effect on thrombopoiesis of patient Igs purified after remission was negative as no differences in GFP expression could be observed.

It is not yet clear why the patient experienced many lifethreatening and massive gastrointestinal bleedings. This phenotype is not present in GATA1-deficient patients (14-23). We hypothesize that the anti-GATA1 autoantibody crossreacts with the other GATA factors. As GATA2 is a factor necessary for myeloid differentiation $(4,5,29-31)$ and blockade of GATA2 can lead to the increased number of myeloid precursors in the peripheral blood. GATA2, 3, and 6 are known to be involved in endothelial function $(4,5,32,33)$ and GATA 4, 5 and 6 are necessary for gastric epithelium differentiation (9,34-38). As such, anti-GATA autoantibodies could play a role in the development of hemorrhagic gastritis and gastrointestinal hemangiomata. GATA1 is also known to be important for erythropoiesis $(1,3,4)$, but no influence on erythropoiesis could be observed in the CFU assays or in the mouse experiments. Concerning the mechanism by which the antibody could be taken up by megakaryocytes or their precursors, we could only hypothesize that the antibody is endocytosed and reaches the nucleus in some way, as GATA1 is not located at the surface of hematopoietic stem cells or megakaryocytes. The exact mechanism remains to be unraveled.

It is also not clear why the patient developed the antibody against a transcription factor. The hepatitis B immunization could have triggered the autoantibody formation. The question of a possible connection between vaccination and autoimmunity is surrounded by controversy. Some autoimmune phenomena are clearly related to immunization (e.g. GuilainBarre syndrome) $(39,40)$. Tetanus toxoid, influenza vaccines, polio vaccine, and others have been related to phenomena ranging from autoantibodies to full-blown illness (such as rheumatoid arthritis) (41). The causality between vaccines, such as against measles and hepatitis $\mathrm{B}$, has been the subject of a debate during multiple years $(42,43)$. 
In conclusion, this is the first report of an anti-GATA1 autoantibody as a new pathogenic mechanism leading to refractory thrombocytopenia. Future studies evaluating the autoimmune response at this young age are needed to address a possible involvement of immunization and to consider a parallel but still unexplained mechanism as in congenital transient neutropenia and autoimmune neutropenia of infancy.

\section{REFERENCES}

1. Patient RK, McGhee JD 2002 The GATA family (vertebrates and invertebrates). Curr Opin Genet Dev 12:416-422

2. Martin DI, Zon LI, Mutter G, Orkin SH 1990 Expression of an erythroid transcription factor in megakaryocytic and mast cell lineages. Nature 344:444-447

3. Romeo PH, Prandini MH, Joulin V, Mignotte V, Prenant M, Vainchenker W, Marguerie G, Uzan G 1990 Megakaryocytic and erythrocytic lineages share specific transcription factors. Nature 344:447-449

4. Weiss MJ, Orkin SH 1995 GATA transcription factors: key regulators of hematopoiesis. Exp Hematol 23:99-107

5. Wilson DB, Dorfman DM, Orkin SH 1990 A nonerythroid GATA-binding protein is required for function of the human preproendothelin-1 promoter in endothelial cells. Mol Cell Biol 10:4854-4862

6. Ho IC, Vorhees P, Marin N, Oakley BK, Tsai SF, Orkin SH, Leiden JM 1991 Human GATA-3: a lineage-restricted transcription factor that regulates the expression of the $\mathrm{T}$ cell receptor alpha gene. EMBO J 10:1187-1192

7. Ko LJ, Yamamoto M, Leonard MW, George KM, Ting P, Engel JD 1991 Murine and human T-lymphocyte GATA-3 factors mediate transcription through a cisregulatory element within the human T-cell receptor delta gene enhancer. Mol Cell Biol 11:2778-2784

8. Laverriere AC, MacNeill C, Mueller C, Poelmann RE, Burch JB, Evans T 1994 GATA-4/5/6, a subfamily of three transcription factors transcribed in developing heart and gut. J Biol Chem 269:23177-23184

9. Gao X, Sedgwick T, Shi YB, Evans T 1998 Distinct functions are implicated for the GATA-4, -5 , and -6 transcription factors in the regulation of intestine epithelial cell differentiation. Mol Cell Biol 18:2901-2911

10. Tsai SF, Martin DI, Zon LI, D'Andrea AD, Wong GG, Orkin SH 1989 Cloning of cDNA for the major DNA-binding protein of the erythroid lineage through expression in mammalian cells. Nature 339:446-451

11. Evans T, Felsenfeld G 1989 The erythroid-specific transcription factor Eryf1: a new finger protein. Cell 58:877-885

12. Martin DI, Orkin SH 1990 Transcriptional activation and DNA binding by the erythroid factor GF-1/NF-E1/Eryf 1. Genes Dev 4:1886-1898

13. Tsang AP, Visvader JE, Turner CA, Fujiwara Y, Weiss MJ 1997 FOG, a multitype zinc finger protein, acts as a cofactor for transcription factor GATA-1 in erythroid and megakaryocytic differentiation. Cell 90:109-119

14. Nichols KE, Crispino JD, Poncz M, White JG, Orkin SH, Maris JM, Weiss MJ 2000 Familial dyserythropoietic anaemia and thrombocytopenia due to an inherited mutation in GATA1. Nat Genet 24:266-270

15. Freson K, Devriendt K, Matthijs G, Van Hoof A, De Vos R, Thys C, Minner K, Hoylaerts MF, Vermylen J, Van Geet C 2001 Platelet characteristics in patients with $\mathrm{X}$-linked macrothrombocytopenia because of a novel GATA1 mutation. Blood 98:85-92

16. Freson K, Matthijs G, Thys C, Marien P, Hoylaerts MF, Vermylen J, Van Geet C 2002 Different substitutions at residue D218 of the X-linked transcription factor GATA1 lead to altered clinical severity of macrothrombocytopenia and anemia and are associated with variable skewed X inactivation. Hum Mol Genet 11:147-152

17. Mehaffey MG, Newton AL, Gandhi MJ, Crossley M, Drachman JG 2001 X-linked thrombocytopenia caused by a novel mutation of GATA-1. Blood 98:2681-2688

18. Del Vecchio GC, Giordani L, De Santis A, De Mattia D 2005 Dyserythropoietic anemia and thrombocytopenia due to a novel mutation in GATA-1. Acta Haematol 114:113-116

19. Yu C, Niakan KK, Matsushita M, Stamatoyannopoulos G, Orkin SH, Raskind WH 2002 X-linked thrombocytopenia with thalassemia from a mutation in the amino finger of GATA-1 affecting DNA binding rather than FOG-1 interaction. Blood 100:2040-2045
20. Balduini CL, Pecci A, Loffredo G, Izzo P, Noris P, Grosso M, Bergamaschi G, Rost V, Magrini U, Ceresa IF, Conti V, Poggi V, Savoia A 2004 Effects of the R216Q mutation of GATA-1 on erythropoiesis and megakaryocytopoiesis. Thromb Haemost 91:129-140

21. Tubman VN, Levine JE, Campagna DR, Monahan-Earley R, Dvorak AM, Neufeld EJ, Fleming MD 2007 X-linked gray platelet syndrome due to a GATA1 Arg216Gln mutation. Blood 109:3297-3299

22. Phillips JD, Steensma DP, Pulsipher MA, Spangrude GJ, Kushner JP 2007 Congenital erythropoietic porphyria due to a mutation in GATA1: the first trans-acting mutation causative for a human porphyria. Blood 109:2618-2621

23. Kratz CP, Niemeyer CM, Karow A, Volz-Fleckenstein M, Schmitt-Gräff A, Strahm B 2008 Congenital transfusion-dependent anemia and thrombocytopenia with myelodysplasia due to a recurrent GATA1(G208R) germline mutation. Leukemia 22:432-434

24. Freson K, De Vos R, Wittevrongel C, Thys C, Defoor J, Vanhees L, Vermylen J, Peerlinck K, Van Geet C 2005 The TUBB1 Q43P functional polymorphism reduces the risk of cardiovascular disease in men by modulating platelet function and structure. Blood 106:2356-2362

25. Stevens RA, Lempicki RA, Natarajan V, Higgins J, Adelsberger JW, Metcalf JA 2006 General immunologic evaluation of patients with human immunodeficiency virus infection. In: Detrick B, Hamilton RG, Folds JD (eds) Manual of Molecula and Clinical Laboratory Immunology. 7th ed. ASM Press, Washington, DC, pp $847-861$

26. Westerfield M 1994 The Zebrafish Book. University of Oregon Press, Eugene, OR

27. Kimmel CB, Ballard WW, Kimmel SR, Ullmann B, Schilling TF 1995 Stages of embryonic development of the zebrafish. Dev Dyn 203:253-310

28. Lin HF, Traver D, Zhu H, Dooley K, Paw BH, Zon LI, Handin RI 2005 Analysis of thrombocyte development in CD41-GFP transgenic zebrafish. Blood 106:3803-3810

29. Zhang SJ, Ma LY, Huang QH, Li G, Gu BW, Gao XD, Shi JY, Wang YY, Gao L, Cai X, Ren RB, Zhu J, Chen Z 2008 Gain-of-function mutation of GATA-2 in acute myeloid transformation of chronic myeloid leukemia. Proc Natl Acad Sci USA 105:2076-2081

30. Nagai T, Harigae H, Ishihara H, Motohashi H, Minegishi N, Tsuchiya S, Hayashi N, Gu L, Andres B, Engel JD 1994 Transcription factor GATA-2 is expressed in erythroid, early myeloid, and CD34+ human leukemia-derived cell lines. Blood 84:1074-1084

31. Rodrigues NP, Boyd AS, Fugazza C, May GE, Guo Y, Tipping AJ, Scadden DT, Vyas P, Enver T 2008 GATA-2 regulates granulocyte-macrophage progenitor cell function. Blood 112:4862-4873

32. Simon MP, Tournaire R, Pouyssegur J 2008 The angiopoietin-2 gene of endothelial cells is up-regulated in hypoxia by a HIF binding site located in its first intron and by the central factors GATA-2 and Ets-1. J Cell Physiol 217:809-818

33. Umetani M, Mataki C, Minegishi N, Yamamoto M, Hamakubo T, Kodama T 2001 Function of GATA transcription factors in induction of endothelial vascular cell adhesion molecule-1 by tumor necrosis factor-alpha. Arterioscler Thromb Vasc Biol 21:917-922

34. Haveri $\mathrm{H}$, Westerholm-Ormio M, Lindfors K, Maki M, Savilahti E, Andersson LC, Heikinheimo M 2008 Transcription factors GATA-4 and GATA-6 in normal and neoplastic human gastrointestinal mucosa. BMC Gastroenterol 8:9

35. Dimaline R, Campbell BJ, Watson F, Sandvik AK, Struthers J, Noble PJ 1997 Regulated expression of GATA-6 transcription factor in gastric endocrine cells. Gastroenterology 112:1559-1567

36. Maeda M, Kubo K, Nishi T, Futai M 1996 Roles of gastric GATA DNA-binding proteins. J Exp Biol 199:513-520

37. Jacobsen CM, Narita N, Bielinska M, Syder AJ, Gordon JI, Wilson DB 2002 Genetic mosaic analysis reveals that GATA-4 is required for proper differentiation of mouse gastric epithelium. Dev Biol 241:34-46

38. Jacobsen CM, Mannisto S, Porter-Tinge S, Genova E, Parviainen H, Heikinheimo M, Adameyko II, Tevosian SG, Wilson DB 2005 GATA-4:FOG interactions regulate gastric epithelial development in the mouse. Dev Dyn 234:355-362

39. Stratton KR, Howe CJ, Johnston RB 1994 Adverse events associated with childhood vaccines other than pertussis and rubella. JAMA 271:1602-1605

40. Koski CL 1992 Humoral mechanisms in immune neuropathies. Neurol Clin 10:629_ 649

41. Shoenfeld Y, Aron-Maor A 2000 Vaccination and autoimmunity_-Vaccinosis': a dangerous liaison? J Autoimmun 14:1-10

42. Herroelen L, de Keyser J, Ebinger G 1991 Central nervous system demyelination after immunization with recombinant hepatitis B vaccine. Lancet 338:1174-1175

43. Nadler JP 1993 Multiple sclerosis and hepatitis B vaccination. Clin Infect Dis 17:928-929 